\title{
On the evaluation of debris flows dynamics by means of mathematical models
}

\author{
M. Arattano ${ }^{1}$ and L. Franzi ${ }^{2}$ \\ ${ }^{1}$ CNR-IRPI, Strada delle Cacce 73, 10135 Torino, Italy \\ ${ }^{2}$ Regione Piemonte, Via Petrarca 44, 10100 Torino, Itay \\ Received: 17 September 2002 - Revised: 23 December 2002 - Accepted: 8 January 2003
}

\begin{abstract}
The prediction of debris flow dynamic characteristics in a debris flow prone torrent is generally made through the investigation of past events. This investigation can be carried out through a survey of the marks left by past debris flows along the channel and through a detailed analysis of the type and shape of the deposits found on the debris fan. The rheological behaviour of future debris flows can then be inferred from the results of these surveys and their dynamic characteristics can be estimated applying well known formulas proposed in literature. These latter will make use of the assumptions on the rheological behaviour previously made. This type of estimation has been performed for a debris flow occurred in an instrumented basin, on the North-Eastern Italian Alps, in 1996 and the results have been compared to those obtained by means of a mathematical simulation. For the calibration of the mathematical model the limnographs recorded by three different ultrasonic gauges installed along a torrent reach on the fan were used. The comparison evidenced the importance of time data recordings for a correct prediction of the debris flows dynamics. Without the availability of data recordings, the application of formulas based only on assumptions derived from field analysis could be misleading.
\end{abstract}

\section{Introduction}

An efficient hazard zoning and the design of effective countermeasures against debris-flows require the estimation of several important parameters. Examples of these latter are: event magnitude, total volume that can be deposited on the debris fan, composition of the water sediment mixture, rheological behaviour of this latter, triggering rainfalls, etc. (Taylor and Hearn, 2000). Generally these parameters can be estimated by means of accurate geological surveys (Suwa and Yamakoshi, 2000; Ayotte and Hungr, 2000; Jackson et al., 1987) and by means of an analysis of past debris flow events that occurred in the basin that is being investigated.

Correspondence to: M. Arattano (m.arattano@irpi.to.cnr.it)
The dynamic characteristics of a debris flow, such as peak discharge, flow velocity, impact force, runout etc. need also to be evaluated, either on the basis of the available data regarding past events, by the application of empirical formulas or by more complex numerical simulation models (Rickenmann, 1999).

Nowadays there are no rigorous methods that allow to determine the probability of debris flow occurrence and to predict its peak discharge and flow velocity (Rickenmann, 1999). Besides, no dynamic model has been systematically calibrated (Ayotte amd Hungr, 2000), as most models have been fitted to just few isolated case histories. Therefore the evaluation of the debris flow dynamics and the consequent hazard assessment need different approaches, according to the particular situations that need to be addressed (Heumader, 2000).This is due to the high variability of the geological characteristics of the basin, of the sediment compositions and to the different rheological behaviours of debris flows. The number of field observations and the information on past events are often rather limited, so that the recourse to empirical formulas or more complex mathematical models often represents the only possible way to deal with the problem.

In this paper the dynamic behaviour of a debris flow occurred in the Moscardo Torrent, an instrumented basin on the North-Eastern Italian Alps, on 22 June 1996 is estimated using different computational approaches. The results have then been compared to those obtained by means of a mathematical simulation. For the simulation the limnographs have been used that were recorded by three different ultrasonic gauges installed along an almost straight and deeply incised reach of the torrent.

\section{Description of the real case debris flow chosen for the simulation.}

The Moscardo torrent is a small torrent located on the Eastern Italian Alps that has been affected in the past by several debris flows (Fig. 1, Marchi et al., 2002). It drains an area of about $4 \mathrm{~km}^{2}$ ranging in elevation from $890 \mathrm{~m}$ to $2043 \mathrm{~m}$. 


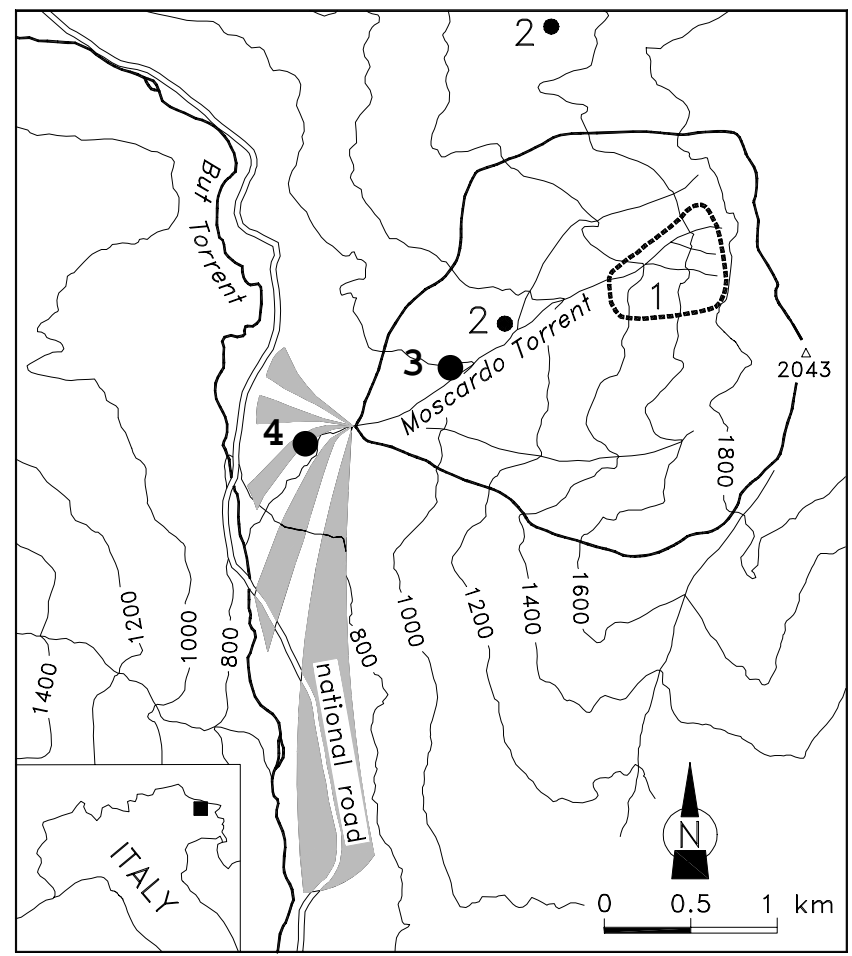

Fig. 1. The Moscardo Torrent basin and its alluvial fan. 1: debris flow initiation area; 2 : raingauges; 3 : location of the ultrasonic sensors.

The debris flow initiation area is pointed out in Fig. 1. The particles size of the water sediment current usually ranges from clay to course rocky fragment; fine material (silt and clay) averages $20-25 \%$ of the debris matrix (Arattano et al., 1997).

In 1989 two ultrasonic sensors were placed on the fan of the torrent, where the bed slope is approximately $10 \%$ and the river reach is quite straight. In 1996 a third sensor was added upstream of the previously installed sensors. The distance between the first and the second sensor was $143 \mathrm{~m}$. The distance between the second and the third sensor was $226 \mathrm{~m}$. The sensors were suspended over the torrent by a cable sustained by steel stakes. Flow height was measured and recorded once a second. In 1996 a fixed video camera was also installed close to the upstream gauging station (Arattano and Grattoni, 2000) and the video recording was triggered by the upstream ultrasonic sensor when a sudden increase of the stage was detected.

The debris flow event occurred on 22 June 1996 was characterised by a first water-sediment wave that preceded the arrival of the main front. This latter consisted mainly of large boulders immersed in a dense muddy matrix and was then followed by three secondary waves, which are visible in the limnographs of Fig. 2. The debris flow was contained within the banks of the torrent and there was no overfloading: no tracks were in fact found on the ground surrounding the torrent banks. The event was also videorecorded by the automated system triggered by the upstream ultrasonic sensor.

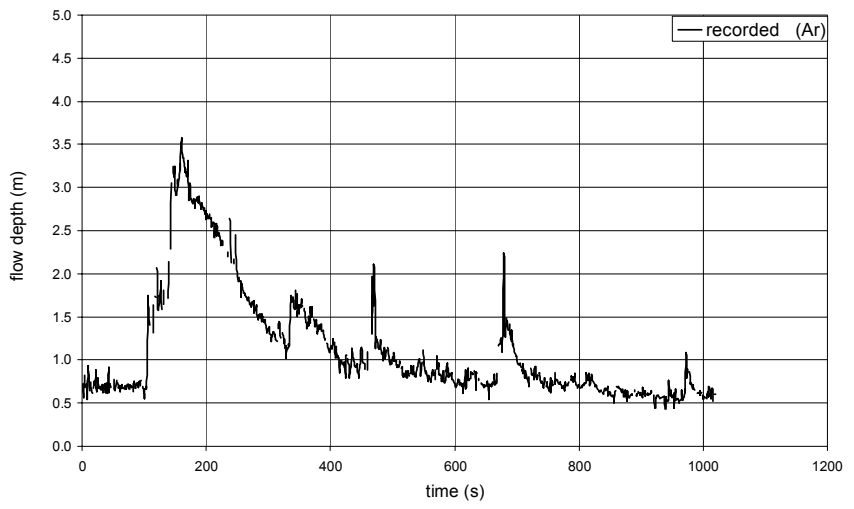

Fig. 2. Recorded flow depth at the upstream gauging station.

The video images confirm all the above observations and also show that the three smaller waves following the main front did not contain any large boulder and mainly consisted of a dense mud. The peak discharge of the event was calculated on the basis of the measured mean front velocity and was about $140 \mathrm{~m}^{3} / \mathrm{s}$ (the peak discharge ranged between $132 \mathrm{~m}^{3} / \mathrm{s}$ measured at the upstream station and $151 \mathrm{~m}^{3} / \mathrm{s}$ measured at the downstream one) (Marchi et al., 2002).

Topographic surveys were also carried out to provide the data for the calibration of a software used to process the recorded images and measure surface velocity (Arattano and Grattoni, 2000).

\section{The mathematical model}

The mathematical model employed for the simulation assumes a homogeneous water-sediment current over a rigid bed in unsteady conditions. No deposition effects have been taken into account, implicitly assuming that no degradation or aggradation processes occurred along the channel. Due to the incised cross-sections shape and to the straight reach which is here under investigation, the propagation processes occurred during the event are assumed to be monodimensional. Applying the mass and momentum conservation laws, a system of two partial differential equations is obtained and solved with an implicit finite-difference scheme.

$$
\left\{\begin{aligned}
\frac{\partial h}{\partial t}+\frac{1}{b} \frac{\partial Q}{\partial x} & =0 \\
\frac{\partial Q}{\partial t}+g A \frac{\partial h}{\partial x} \cos (\theta)+\frac{\partial}{\partial x}\left(\frac{Q^{2}}{A}\right) & \\
+g A S_{f}-g A \tan (\theta) & =0
\end{aligned}\right.
$$

where:

$Q$ : water-sediment discharge;

$A$ : area;

$b$ : free surface width;

$h$ : flow depth;

$\theta$ : bed slope angle;

$S_{f}$ : friction loss;

$x$ : bed-parallel coordinate (positive downstream);

$g$ : gravity acceleration;

$t$ : time. 
Table 1. Values of $n$ for the different types of rheological models summarized by Pierson and Costa (1987)

\begin{tabular}{lc}
\hline Rheological behaviour & Parameter " $n$ " \\
\hline Pseudoplastic fluid with a yield value & $>2$ \\
Pseudoplastic fluid without a yield value & $>2$ \\
Newtonian fluid (laminar motion) & 2 \\
Bingham fluid & 2 \\
Dilatant fluid with a yield value & $1<n<2$ \\
Dilatant without a yield value & $1<n<2$ \\
Turbulent motion & $<1$ \\
& \\
\hline
\end{tabular}

The rheological properties of the water sediment mixture must be specified to solve the system (1). The following closure equation has been used (Nsom et al., 1998):

$S_{f}=\frac{U^{2}}{c^{2} h^{2 n}}$

where $c$ and $n$ are two parameters. In particular $n$ is given by:

$n=\frac{\eta+1}{\eta}$

where $\eta$ is named flow behaviour index and depends on the rheological behaviour of the water sediment mixture.

The different $n$ values applying for the different existing rheological models have been summarised by Pierson and Costa (1987) (Table 1).

Rickenmann (1999) finds that the best value for $n$ is $1 / 3$, according to the results of some numerical simulations of unsteady debris flow surges (Koch, 1998).

Theoretical and laboratory investigations have been made by Takahashi (1991), who proposed $n=1.5$ for a dilatant flow behaviour (the dilatant flow behaviour applies for stony debris flows). Moreover, Takahashi (1991) found that the $c$ coefficient depends on the sediment concentration $C$, the interstitial fluid density $\rho_{m}$ and the mean grain size $d$ according to the following relationship (Takahashi and Nakagawa, 1993):

$$
\begin{aligned}
c= & \frac{2}{5 d} \sqrt{g}\left\{\frac{1}{0.02} \cdot\left(C+(1-C) \frac{\rho_{m}}{\rho_{s}}\right)\right\}^{1 / 2} \\
& \cdot\left\{\left(\frac{C_{*}}{C}\right)^{1 / 3}-1\right\}
\end{aligned}
$$

where $\rho_{S}$ is a the particle density and $C_{*}$ the maximum packing concentration. The $C$ value is given by the formula proposed by Takahashi (1991, p.35).

According to Rickenmann the $c$ coefficient depends also on the parameter $n$ and on the debris flow peak discharge (Rickenmann, 1999).

Finally Coussot (1994) proposed the assumption of the Herschel-Bulkley model to simulate muddy debris flows and mudflows. The Herschel-Bulkley model assumes $n=3$.
In the mathematical simulation here described different values for $c$ and $n$ have been tested, in order to find the $[c, n]$ couple that allowed to best fit the considered debris flow event.

A steady flow has been assumed for the initial conditions, for the entire length of the torrent reach; the solved equations are the same as those in Eq. (1), except for the terms that depend on time, that are set equal to zero. This assumption does not affect the obtained results, since the debris flow discharges and flow depths (as well as their variation in time) are much larger than those of the initial water-sediment current.

The upstream boundary conditions for $h$, that have been assumed in the simulation, are given by the upstream recorded limnograph (limnograph A).

$$
\left\{\begin{array}{l}
t=0 \\
U=U(x) ; h=h(x) \text { for } 0<x<L ; \text { steadyflow }
\end{array}\right.
$$

$\left\{\begin{array}{l}x=0 \\ U=f[h(0, t)] ; h=h(t) \text { for } 0 \leq t<\infty\end{array}\right.$

where $L$ is the length of the river reach, equal to the distance between the first and the third limnograph. As indicated before, the $U(0, t)=f[h(0, t)]$ relation in the upstream reach depends on the choice of the simulation parameters, according to Eq. (2). As the $h$ values are those recorded in the first limnograph, the uncertainty in the estimation of $U$ (and consequently in the estimation of the debris flow discharge,) is much smaller than that affecting other models, where both the upstream conditions have to be estimated (Honda and Egashira, 1997; Hirano et al., 1997). The assumption of uniform flow conditions in the upstream boundary can be found in other models (e.g. Hirano et al., 1997; Suzuki et al., 1993; Arattano and Savage, 1994 for kinematic models). For steep bed slopes, the assumption of uniform flow conditions can be the most reliable, because there is a predominance of the fourth and fifth term in the left side of the second equation in system (1) (Cunge et al., 1980).

The simulations, performed for different $c$ and $n$ values maintaining the same boundary $h(0, t)$ and initial conditions, fit fairly well the recorded limnographs for the following values of the $(c, n)$ pair: $c=14 \mathrm{~m}^{0.8} / \mathrm{s}$ and $n=0.2$.

As shown in Fig. 3, the simulated limnograph $(\mathrm{Bc})$ fits fairly well the limnograph recorded at the second gauging station $(\mathrm{Br})$. The simulation reproduces well all the four waves of the limnograph. The computed peak discharge is about $170 \mathrm{~m}^{3} / \mathrm{s}$, that is about $21 \%$ greater than the mean peak discharge measured at the three stations and about $12 \%$ greater than the peak discharge measured at the downstream station. Thus the simulation fits fairly well also the values of the peak discharge that have been measured (Marchi et al., 2002).

As far as the limnograph recorded by the third gauging station is concerned (Fig. 4), the simulation (Cc) fits only partially the first wave of the limnograph. This is due to the probable occurrence of some depositional processes in 


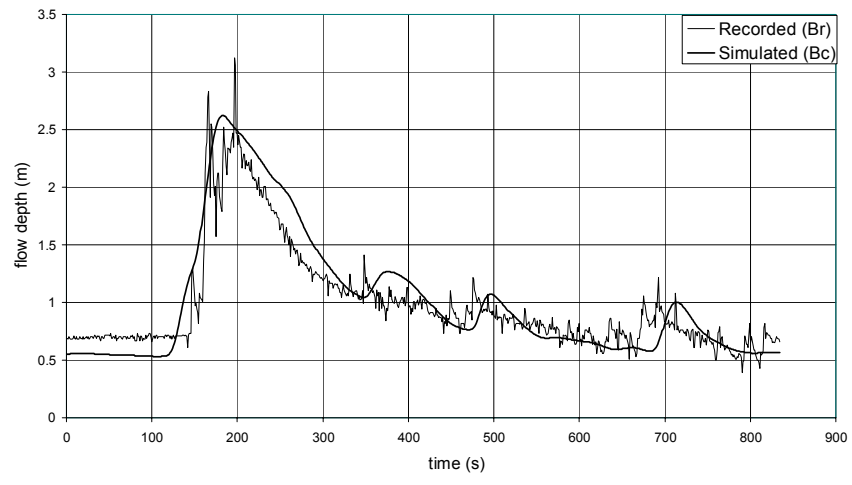

Fig. 3. Comparison between recorded flow depth in the second gauge station and simulated one.

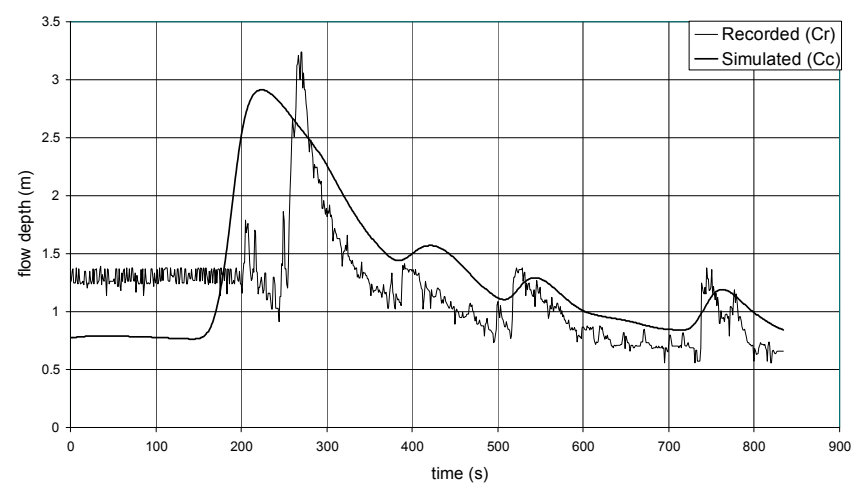

Fig. 4. Comparison between recorded flow depth in the third gauge station and simulated one.

the torrent reach between the second and the third gauging station. Some photos taken after the debris flow occurrence seem to confirm this hypothesis (Fig. 5). This is also evident if the total area under the curve of the first wave $(\mathrm{Cr})$ is compared to the areas under the (Ar) and (Br) curves. Probably the deposition of a huge boulder (Fig. 5) caused the debris flow to slow down and a partial deposition of material occurred, affecting also the flow of the second wave in $(\mathrm{Cr})$. Actually the third and fourth simulated waves in $(\mathrm{Cc})$ fit again well the recorded waves in (Cr). The computed peak discharge is about $160 \mathrm{~m}^{3} / \mathrm{s}$, comparable with the estimated value of $151 \mathrm{~m}^{3} / \mathrm{s}$ (Marchi et al., 2002).

\section{Impact forces}

It is well known from literature that the impact forces exerted by a debris flow against an anthropic fixed structure depend on the debris flow velocity and discharge, as well as on the density of the flowing mixture. According to Armanini and Scotton (1993), the impact forces have two components, that are given by (per unitary width):

$$
|\boldsymbol{F}|=\left|\boldsymbol{F}_{1}\right|+\left|\boldsymbol{F}_{2}\right|=\rho Q|\boldsymbol{U}|+\frac{1}{2} g \rho h^{2}
$$

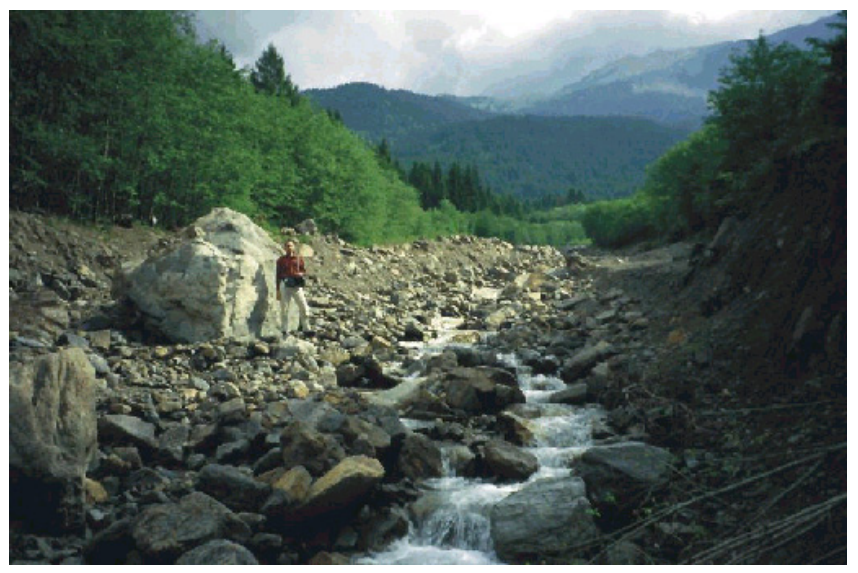

Fig. 5. A large boulder was deposited by the 22 June 1996 debris flow in the torrent reach between the second and third gaging station. Probably this large boulder caused a temporary stop of the current and/or a partial deposition.

the evaluation of the second term in Eq. (7) does not depend on the choice of the parameters $c$ and $n$ in the simulation, thus only the first term will be considered in the following discussion.

Assuming that $\rho$ is the same, different estimations of $Q$ and $U$ are obtained applying empirical relationships, theoretically derived equations or the simulation results obtained by the proposed mathematical model.

Following Takahashi's approach, and assuming uniform flow conditions, an $n$ value equal to 1.5 , a $C$ value equal to 0.13 (by applying Takahashi (1991) formula), a $C_{*}$ value equal to 0.7 , a $\rho_{m}$ value equal to $1000 \mathrm{~kg} / \mathrm{m}^{3}$, with a representative sediment diameter $d$ equal to $0.4 \mathrm{~m}$ the value of $c$ results to be $14 \mathrm{~m}^{-0.5} / \mathrm{s}$.

The assumption of the Herschel-Bulkley model proposed by Coussot (1994) would lead to unrealistic values.

The application of the methodology proposed by Rickenmann (1999) for a peak discharge equal to $170 \mathrm{~m}^{3} / \mathrm{s}$, yields to a $c$ value of $10 \mathrm{~m}^{0.66} / \mathrm{s}$.

The comparison of the results obtained by the different approaches is shown in Fig. 6, as far as the first component of the impact force is concerned. Figure 6 evidences the role played by the choice of the rheological and friction parameters in the evaluation of velocity and discharge. The use of formulas in uniform flow conditions, either obtained theoretically or empirically, may give very different results according to the assumed behaviour of the flow. In particular the assumption of values that hold for a dilatant flow behavior $(n=1,5)$, as that proposed by Takahashi, would result in an overestimation of the impact force for the examined event. With the assumption of the Herschel-Bulkley model proposed by Coussot (1994) the overestimation would be even greater. Since the simulation parameters can be indirectly estimated only for single debris flow events, the dynamics of debris flows which will occur in the future can be correctly predicted only if the rheological behaviour of the de- 


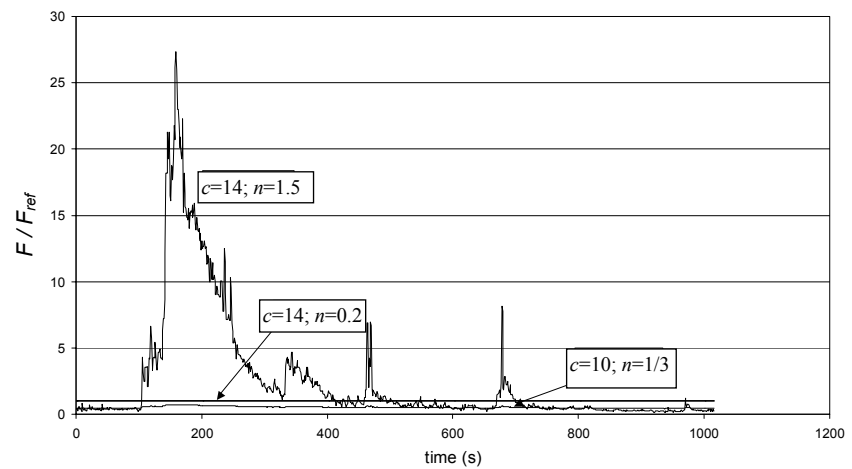

Fig. 6. Impact forces. $F_{\text {ref }}$ is the component of the impact force when $c$ and $n$ are the same as those used in the simulation.

bris flow is assumed to remain unchanged. This is usually not the case. Consequently a more comprehensive assessment of the more likely impacts produced by future debris flows against structures can be done only by considering different rheological behaviours and examining their potential effects. The results here presented put into evidence that calibration is strongly necessary, preferably made by means of simulation models that take into account the presence of unsteady conditions. Otherwise the assumption would be only based on arbitrary hypothesis. Even rheological tests performed on samples collected in the field (Coussot et al., 1998) might be inadequate, apart from the difficulties encountered in using large rheometers and their costs. In fact these tests would reveal only the behaviour of the portion of the wave where the sample comes from, while the global behaviour of the entire wave might be significantly different (Coussot et al., 1998).

The performed comparison evidenced the importance of the availability of time data recordings, such as those obtained through ultrasonic devices, for a correct prediction of the debris flow dynamics. Without such recordings the application of formulas based on assumptions derived only from field analysis could be in fact misleading.

\section{Conclusions}

The design of countermeasures and the hazard zoning in debris flow prone basins need an estimation of the debris flow magnitude and require the knowledge of its dynamic characteristics. These latter depend on many variables that are often difficult to be indirectly estimated. Rheological tests performed on samples collected in the field, besides being difficult to perform and expensive, might give inadequate results. The application of empirical formulas and the arbitrary assumption of a rheological behaviour might give misleading results as far as the estimation of the impact force is concerned. This has been evidenced in this paper by the calibration of a numerical model on the basis of some recordings obtained in the field through ultrasonic sensors. The model has allowed to indirectly estimate the rheological parameters of the recorded debris flow. A calibration such as that described in this paper can only be performed if limnographs recorded at different locations along the torrent are available and the boundary geometry of the torrent has been surveyed. The obtained rheological parameters of the recorded debris flow revealed that the assumption of values that hold for a dilatant or Herschel-Bulkley behavior would result in an overestimation of the impact force for the examined event. The results that have been obtained evidenced the importance of the availability of field data recorded through installed equipment for a correct prediction of the debris flows dynamics. Without such recordings the application of formulas based on assumptions derived only from field analysis could in fact be misleading. Since future debris flows in the same basin may show different rheological behaviours, it is also important to confirm the obtained results by means of the simulation of other debris flow events. Monitoring activities in the Moscardo basin will be continued to provide more data for this purpose.

\section{References}

Arattano, M., Deganutti, A. M., and Marchi, L.: Debris flow monitoring activities in an instrumented watershed on the Italian alps, Proceedings of the First International ASCE Conference on Debris-Flow Hazard Mitigation: Mechanics, Prediction and Assessment, San Francisco, Ca, August 7-9, 506-515, 1997.

Arattano, M. and Grattoni, P.: Using a fixed video camera to measure debris flow surface velocity, Second International Congress on Debris Flows Hazard Mitigation: mechanics, prediction and assessment, 273-281, 2000.

Arattano, M. and Savage, W. Z.: Modelling debris flows as kinematic waves, Bulletin of the IAEG, 49, 95-105, 1994.

Armanini, A. and Scotton, P.: On the dynamc impact of a debris flow on structures, Proceeding of the XXV IAHR Congress, Tokyo, 203-210, 1993.

Ayotte, D. and Hungr, O: Calibration of runout prediction model for debris flows avalanches, Second International Congress on Debris Flows Hazard Mitigation: mechanics, prediction and assessment, 505-514, 2000.

Coussot, P.: Steady, laminar, flow of concentrated mud suspensions in open channel, J. Hydr. Res., 32, 535-539, 1994

Cunge, J. A., Holly, Jr., F. M., and Verwey, A.: Practical aspect of computational River hydralics, Pitman Publishing Limited, London, 1980.

Coussot, P., Laigle, D., Arattano, M., Deganutti, A. M., and Marchi, L.: Direct determination of rheological characteristics of a debris flow, J. Hydr. Eng., ASCE 124, 8, 865-868, 1998.

Marchi, L., Arattano, M., and Deganutti, A. M.: Ten years of debris flows monitoring in the Moscardo Torrent (Italian Alps), Geomorphology, 46, 1-17, 2002.

Heumader, J.: Technical debris flow countermeasures in Austria A review, Second International Congress on Debris Flows Hazard Mitigation: mechanics, prediction and assessment, 553-564, 2000.

Hirano, M., Harada, T., Banuhabib, M. E., and Kawahara, K.: Estimation of hazard area due to debris flow Proceedings of the First International ASCE Conference on Debris-Flow Hazard Mitiga- 
tion: Mechanics, Prediction and Assessment, San Francisco, Ca, August 7-9, 697-706, 1997.

Honda, N. and Egashira, S.: Prediction of debris flow characteristics in mountain torrents, Proceedings of the First International ASCE Conference on Debris-Flow Hazard Mitigation: Mechanics, Prediction and Assessment, San Francisco, Ca, August 7-9, 707-716, 1997.

Jackson, E., Kostaschuk, R. A., and MacDonald, G. M.: Identification of debris flow hazard on alluvial fans in the Canadian Rocky Muntains, Geological Society of America, Reviews in Engineering Geology, Vol II, 1987.

Koch, T.: Testing of various constitutive equations for debris flow modelling, in: Hydrology, Water Resources and Ecology in Headwaters, edited by Kovar et al., IAHS, Publ. No. 248, Merano, Italy, 249-257, 1998.

Nsom, B., Longo, S., Laigle, D., and Arattano, M.: Debris flow rheology and flow resistance, Thematic Report, U.E. contract Debris Flow Risk n ENV4 - CT96 - 0253., 49, 1998.

Pierson, T. C. and Costa, J. E.: A rheological classification of subaerial sediment water flos, Geol. Soc. of America, Rev. and En- gineering and Geology, 7, 1-12, 1987.

Rickenmann, D.: Empirical Relationship for debris flows, Natural Hazards, Kluver Academic Publisher, Printed in Netherlands, 47-77, 1999.

Suwa, H. and Yamakoshi, T.: Estimation of debris flow motion by field survey, Second International Congress on Debris Flows Hazard Mitigation: mechanics, prediction and assessment,293299, 2000.

Suzuky, K., Watanabe, M., Kurihara, T., and Segawa, T.: Field study on debris and sediment flows in a small mountain torrent, Proceeding of the XXV IAHR Congress, Tokyo, 102-108, 1993.

Taylor, G. R. and Hearn, G. J.: Landslide hazard assessment and mitigation: a Hong Kong case study, Second International Congress on Debris Flows Hazard Mitigation: mechanics, prediction and assessment, 461-469, 2000.

Takahashi, T. and Nakagawa, H.: Estimation of flood/debris flow caused by overtopping of a landslide dam, Proceedings of the XXV Congress of I.A.H.R., Tokyo, B, 117-124, 1993.

Takahashi, T.: Debris flows. Rotterdam, Balkema, I.A.H.R. monography, 1991. 